\title{
Un FRAGMENT D'ESCULTURA TROBAT A LA VIL·LA ROMANA DE LES HORTES (Xaló, la Marina Alta)
}

\author{
A fragment of roman sculpture from the villa of Les Hortes (Xalo, la Marina Alta)
}

FERRRAN ARASA I GIL ${ }^{1}$, RUBEN VIDAL I BERTOMEU²

(1) Dpt. de Prehistòria, Arqueologia i H $H^{\mathrm{a}}$ Antiga. Universitat de València. Ferran.Arasa@uv.es (https://orcid.org/0000-0002-7039-141X)

(2) Museu Etnològic de Xaló. rubenvidalbertomeu@gmail.com

RESUMEN:

Donem a conèixer un fragment d'escultura romana que representa una figura infantil alada. Es tracta d'una representació d'Eros que, per les seues reduïdes dimensions, devia formar part d'un grup amb almenys una altra figura major, tal vegada Venus.

Paraules clau: escultura, Eros, vil·la romana.

Abstract:

We present a fragment of a Roman sculpture representing a winged child figure. This is a representation of Eros, which, due to its small size, must have been part of a group with at least another larger figure, perhaps Venus.

Key words: scultpure, Eros, Roman villa. 
La vil·la romana de les Hortes està situada al terme municipal de Xaló, en el territori de l'antiga Dianium (Dénia, la Marina Alta). Va ser localitzada per Rubén Vidal i Bertomeu i Antoni Escoda i Monjo, qui es va trobar la peça que ací presentem. Les restes de la vil·la es troben a la vora de la població, entre el nucli urbà i el riu Xaló, i estan travessades per la carretera CV-745. Del jaciment han pogut identificar-se tres sectors en altres tantes intervencions realitzades entre els anys 2008 i 2016 (Vidal 2019). En el Sector I es va excavar un forn de terrissa molt ben conservat, en el qual es produïen àmfores dels tipus Dressel 2-4 i 26 i material ceràmic de construcció (tegulae, imbrices i lateres) (Vidal i Ortolà 2010); en el Sector II, situat a poca distància de l'anterior, es va trobar una bassa de decantació per al tractament de l'argila del complex industrial amb un paviment fet de tegulae; i en el Sector III, més allunyat dels anteriors, es va descobrir part d'un edifici de la vil-la que deu correspondre a les parts rústica o fructuaria. A la banda septentrional del jaciment es troba la necròpolis, de la qual es coneix la troballa d'una tomba. Els materials recuperats permeten datar-ne l'ocupació entre els ss. I aC i IV dC, quan sembla que degué ser abandonada. La vil·la de les Hortes és un dels tretze jaciments d'època romana que es coneixen al terme municipal de Xaló, set dels quals poden considerar-se vil-les per les característiques de les restes trobades. La seua localització ha permés acréixer el poblament rural del territori de Dianium, on es coneixen més de 150 jaciments, entre ells nombroses vil·les (Gisbert 2003; Frías 2010: 45-113).

La peça que presentem es trobà en un hort situat a l'àrea de dispersió dels materials ceràmics de la vil·la, en una zona que -per les característiques d'aquests- pot correspondre a la seua pars urbana. Es tracta del fragment d'una petita figura de marbre blanc de gra fi, compacte i opac, amb unes dimensions de 3,1 x 1,7 x 1,6 cm (fig. 1). Representa una figura infantil i està trencada per la part superior a l'altura de la base del coll i per la inferior al començament de les cuixes. A l'esquena es veu el principi de les ales, l'atribut que en permet la identificació. El braç dret està trencat a l'altura del muscle i devia estar separat del cos; de l'esquerre falta mig muscle i possiblement estava alçat, el que pot deduir-se també per la inclinació del pit, que té aquest costat un poc més alt. La superfície no presenta danys importants i conserva un fi poliment. El cos està lleugerament inclinat cap a la dreta, per la qual cosa descansava sobre aquesta cama i l'esquerra devia estar un poc flexionada. Els trets anatòmics són suaus, propis d'un nen de curta edat. S'hi distingeixen el plec inguinal del costat esquerre i altres dos plecs horitzontals en la cara posterior de les cuixes. El melic està marcat $\mathrm{amb}$ un petit orifici ovalat disposat verticalment. La secció de la fractura inferior permet veure que la cuixa esquerra és més grossa que la dreta. Pels dos costats té una estreta franja cisellada, sense polir, clarament visible en el dret, que podria explicar-se per la proximitat d'altres figures que impedirien completar-ne el poliment. L'única indumentària que porta és una túnica enrotllada que naix del trencall de les ales i davalla pel maluc dret fins a la zona púbica, on desapareix; al centre, suaus depressions disposades longitudinalment en representen els plecs. Com que no presenta cap orifici per a un pern o la fractura d'un puntill, podem deduir que devia descansar només en la base, tal vegada sobre la mateixa del personatge principal o sobre un suport elevat com un pedestal o columneta.

Pel fet de tractar-se d'una figura infantil que conserva el començament de les ales a l'esquena pot identificar-se sense cap mena de dubtes amb Eros. Segons les dimensions del fragment, la seua alçària total podia ser d'uns 6-7 cm. Devia formar part d'un grup, amb almenys una altra figura principal a la qual acompanyava; la presència de les franges cisellades pels dos costats pot indicar que estava situat entre dues figures pròximes, tal vegada un altre Eros o un dofí. Es trobava en posició estant, amb una mínima torsió corporal cap a l'esquerra i possiblement amb aquest braç allargat i en alt, dirigint-se cap a la figura principal. Per raó de trobar-se tan incomplet és impossible restituir la composició a la qual pertanyia. De la mateixa manera, el fet de no conservar-se'n el cap impedeix fer més precisions estilístiques i cronològiques. A partir de les reduïdes proporcions d'aquesta figura, l'altura del grup pot calcular-se de manera aproximada en $30-40 \mathrm{~cm}$.

En la major part de les composicions d'aquesta mena, la figura d'Eros/Amor va acompanyada de la seua mare Venus, que pot representar-se nua o seminua, o pot anar acompanyada de dos o més putti (Stuveras 1969: $127-$ 135), però en alguns casos la divinitat principal pot ser una altra com Dionís (Blanc i Gury 1986: Eros, Amor, Cupido, LIMC, III: 952-1049). Com a símbol de la innocència i del veritable amor, Eros es representa normalment nu, encara que de vegades porta una clàmide curta, túnica o mantell.

En el període tardohel·lenístic les representacions d'Afrodita acompanyada d'una o més figures d'Eros i altres personatges tenen un important desenvolupament. 


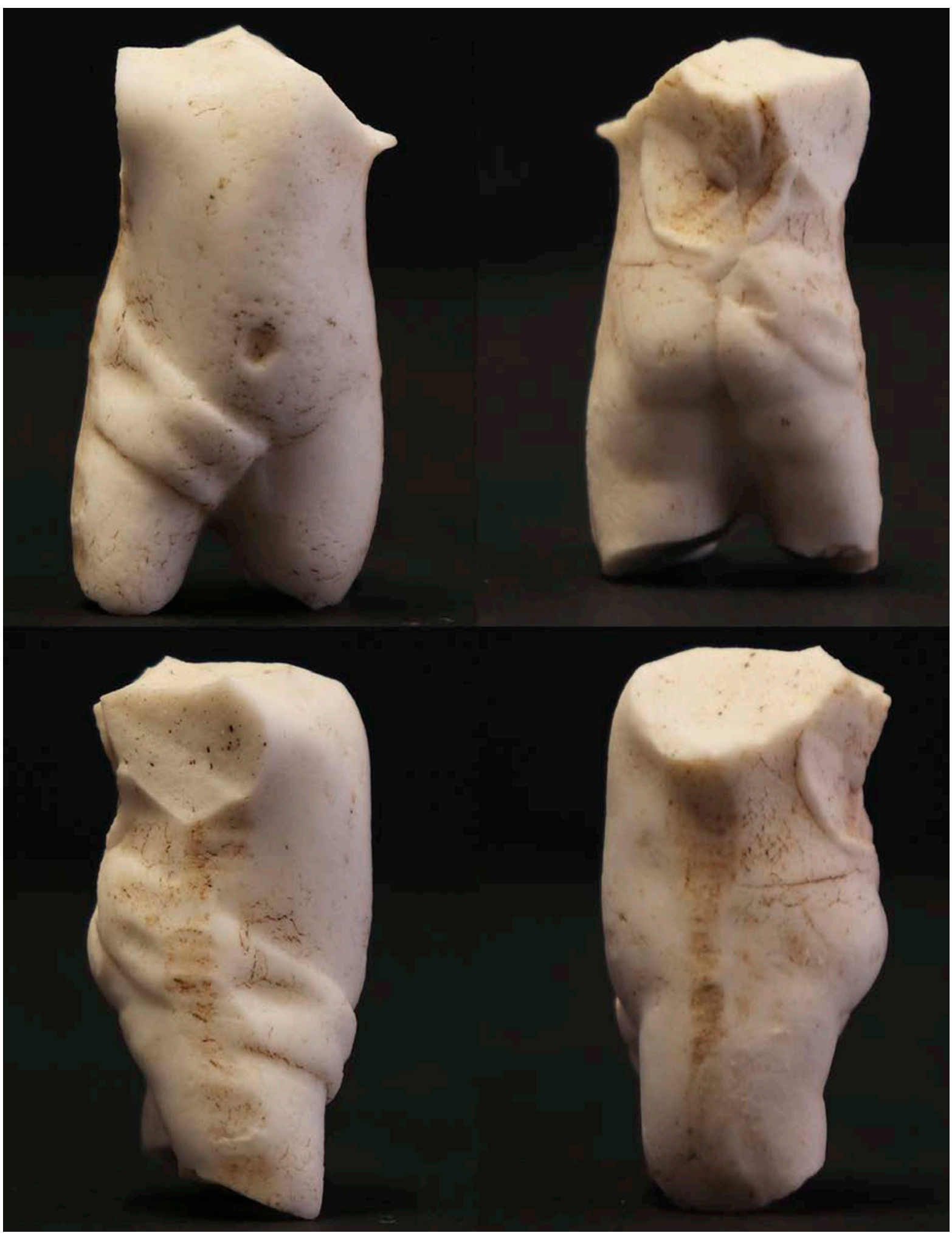

Fig. 1: Figureta d'Eros trobada a la vil·lla romana de les Hortes (Xaló, la Marina Alta). 
Amb posterioritat, en època romana Eros es representa uniformement com un xiquet, ja que aquesta és l'edat preferida per a la seua representació amb Afrodita i també per a la decoració. Les nombroses variants que hi apareixen foren desenvolupades, freqüentment de manera eclèctica, en el període imperial (Machaira 1993). Pot trobar-se de peus a terra i freqüentment porta algun objecte a les mans, com un fruit, una capsa, una torxa o el mateix arc. En aquest cas es representa com un nen de curta edat, de formes arrodonides i suaus, i de manera independent, possiblement en posició frontal.

Un grup de format reduït com aquest pot haver tingut una funció decorativa, per exemple en el jardí del peristil de la pars urbana de la vil·la, com solen trobar-se en les domus pompeianes (Dwyer 1982; Carrella et al. 2008), entre les quals podem citar-ne dues Venus del tipus anadyomene de 36 i 36,5 cm d'altura (Carrella, en Carrella et al. 2008: 79-80, B14; i 93, B27). Les representacions d'aquesta divinitat també decoren ambients termals (Manderscheid 1981: 32-33), com podem veure a Hispània en els casos de Munigua (Sevilla), Lecrín (Granada) i Fuengirola (Málaga) (Koppel 2004: 341342 i 349-350). Tanmateix, de vegades aquestes escultures de reduïdes proporcions tenien una funció de culte $\mathrm{i}$ es trobaven en un larari, com és el cas d'una figureta de $48 \mathrm{~cm}$ de la domus IX 1, 20 de Pompeia (D'Acunto, en Carrella et al. 2008: 163-164, D05). A Hispània Venus i Eros ocupen un lloc destacat entre les divinitats representades en la decoració escultòrica de les domus (Peña 2007-08: 138). Les representacions de Venus també són freqüents en les vil·les, com podem veure a Itàlia (Neudecker 1988: 31). A Hispània se'n coneixen diversos exemples en ambients rurals de la Tarraconense i la Bètica (Koppel 1995: 37; Baena 2007: 209-211; Rodríguez Oliva et al. 2016: 483-484).

Entre els grups de reduit format podem veure alguns exemples com un de l'Allard Pierson Museum d'Amsterdam de tan sols $25,5 \mathrm{~cm}$ d'altura que data del segon o tercer quart del s. II, on Eros $(11,5 \mathrm{~cm})$ es troba dempeus a l'esquerra de Venus $(20,7 \mathrm{~cm})$ i alça el cap i el braç dret cap a la mà esquerra de la seua mare (Moormann 2000: 39-41, núm. 41, Pl. 20); dos del Museu de Side (Turquia) que representen la deessa seminua, el primer de $34,5 \mathrm{~cm}$ d'altura, on el déu nen es troba a l'esquerra del tronc que el separa de la seua mare, que data del s. II dE (Inan 1975: 41-43, núm. 8, Pl. XX, 1-2), i el segon de 37 cm d'altura, amb Eros adormit sobre el tronc que el separa d'aquella, que data d'època severiana (Inan 1975: 152-154, núm. 80, Pl. LXXII, 2). De vegades la deessa va acompanyada, a més del seu fill, per algun altre personatge com Príap, com podem veure en un grup incomplet del Musei Civici di Imola que data d'època tardoimperial i conserva $19 \mathrm{~cm}$ d'altura (Mazzini, en Ortalli i Neri 2007: 227, núm. 131).

En general, els grups de talla reduïda procedeixen principalment del Mediterrani oriental. Tot i que es coneixen des del s. I dC, com és el cas dels exemplars citats de Pompeia, són nombrosos els que daten del s. IV i formen part de les col-leccions escultòriques de domus i vil·les luxoses d'aquesta època (Videbech 2016), com podem veure en els casos de Montmaurin i Chiragan a França (Stirling 2005), Quinta das Longas (Elvas) a Portugal (Nogales et al. 2004), i Valdetorres de Jarama (Madrid) (Puertas et al. 1994; Kousoulas 2014) i Noheda (Cuenca) a Espanya. El marbre d'alguns grups de petit format d'aquestes col-leccions procedeix de les pedreres d'Afrodísies, on la recerca desenvolupada en els darrers anys situa diversos tallers molt actius en aquesta època. Tanmateix, en el cas que ens ocupa les reduïdes dimensions del fragment dificulten la realització de l'anàlisi del marbre i no és possible assegurar-ne la procedència.

Pel que fa als grups, a la península Ibèrica se'n coneixen alguns de petites dimensions. D'Aurgi (Jaén) és una representació de Venus, a la qual li falta el cap, que conserva $38,3 \mathrm{~cm}$ d'altura i té al seu costat un tronc amb una figura al davant que devia representar Eros, de la qual només resten els peus i una ala, que es data en la primera meitat del s. II dE (Baena 2010: 146-151, fig. 12-17). De Pollentia és un grup de Venus flanquejada per dos erots, dels quals se'n conserva un incomplet de $9,3 \mathrm{~cm}$ que porta un cofre amb les seues mans i devia tenir una altura de $12 \mathrm{~cm}$; l'altura del personatge central es calcula en uns 35 cm (Moreno 2016: 35-38, núm. 2, làm. II-III, 1-2). Finalment, a Tarraco se'n conserva un altre grup incomplet de $26 \mathrm{~cm}$ d'altura amb Dionís assegut i Eros dempeus (Koppel 1985: 106-107, núm. 154, Taf. 70, 1).

Al País Valencià coneixem dues figures infantils alades, però de dimensions un poc majors que aquesta. D’Edeta (Llíria, el Camp de Túria) és un fragment inèdit de marbre blanc exposat al Museu Arqueològic de la població que conserva el cos amb una altura de 10,3 cm; i d'Almenara (la Plana Baixa) és un altre també de marbre blanc i $9 \mathrm{~cm}$ d'alçària que correspon a la meitat superior del cos i conserva el cap que gira cap amunt i a la dreta (Arasa 2010: 318-319, fig. 2). 
El fragment mostra un treball acurat en el tractament de l'anatomia i el poliment de la superfície i deixa entreveure que es tractava d'una obra de qualitat. Pel que fa a la cronologia, les reduïdes dimensions de la peça no permeten majors precisions. L'abandonament de la vil·la permet fixar-ne una datació ante quem en el s. IV, per la qual cosa sembla molt improbable que es tracte d'un grup d'època tardana. Per aquestes raons pensem que és raonable una datació aproximada en els ss. I-II dC, en l'etapa de major auge de la vil·la.

\section{BIBLIOGRAFIA}

ARASA, F. (2004): La decoración escultórica de las uillae en el País Valenciano, Actas de la IV Reunión sobre Escultura Romana en Hispania (T. Nogales, L. J. Gonçalves, coords.), Madrid, 229-253.

ARASA, F. (2010): Novedades en la escultura del País Valenciano, Escultura Romana en Hispania VI. Homenaje a Eva Koppel (J. M. Abascal, R. Cebrián, eds.), Murcia, 315-337.

BAENA, L. (2007): Los programas de decoración escultórica en las villae de la Bética, Mainake XXIX, 203-213.

BAENA, L. (2010): Nuevas esculturas de Aurgi (Jaén), Escultura Romana en Hispania VI. Homenaje a Eva Koppel (J. M. Abascal, R. Cebrián, eds.), Murcia, 137-154.

BLANC, N.; GURY, F. (1986): Amor, Cupido, Lexicon Iconographicum Mythologiae Classicae III. 1, Zürich-Munich-Düsseldorf, 952-1049.

CARRELlA, A.; D'ACUNTO, L. A.; INSERRA, N.; SERPE, C. (2008): Marmora Pompeiana nel Museo Archeologico Nazionale di Napoli. Gli arredi scultorei delle case pompeiane, Roma.

DWYER, E. J. (1982): Pompeian domestic sculpture. A study of five pompeian houses and their contents, Roma.

FRÍAS, C. (2010): El poblamiento rural de Dianium, Lucentum, Ilici y la ciudad romana de La Vila Joiosa (siglos II a. C.VII d.C.). Bases para su estudio, Alicante.

GISBERT, J. A. (2003): El territorium de Dianium -Dénia- en el Alto Imperio. La Marina Alta: la producción agrícola y poblamiento, Las ciudades y los campos de Alicante en época romana (J. M. Abascal, L. Abad, coords.), Alicante, 121-143.

INAN, J. (1975): Roman Sculpture in Side, Ankara.

KOPPEL, E. M. (1985): Die römischen Skulpturen von Tarraco, Madrider Forschungen 15.

KOPPEL, E. M. (1995): La decoración escultórica de las villae romanas en Hispania, Poblamiento rural romano en el sureste de Hispania, Murcia, 27-48.

KOPPEL, E. M. (2004): La decoración escultórica de las termas en Hispania, Actas de la IV Reunión sobre escultura romana en Hispania (T. Nogales, L. J. Gonçalves, coords.), Madrid, 339-362.

KOUSOULAS, D. A. (2014): Die Skulpturen aus der villa in Valdetorres, Jarama: Hinweise zur Ikonographie und Verbindung mit der Bildhauerschule von Aphrodisias. Ein Beitrag zur Spätrömischen Skulptur, Actas XVIII Congreso Internacional de Arqueología Clásica, Centro y periferia en el mundo clásico. v. II (J. M. Álvarez, T. Nogales, I. Rodà, eds.), Mérida, 1309-1313.

LIMC = Lexicon Iconographicum Mithologiae Classicae (1981 ss), Zürich-München.

MACHAIRA, V. (1993): Les groupes statuaires d'Aphrodite et d'Eros. Étude stylistique des tipes et de la relation entre les deux divinités pendant l'époque hellenisitique, Athènes.

MANDERSCHEID, H. (1981): Die Skulpturenausstattung des Kaiser zeitlichen Thermenanlagen, Berlin.

MOORMANN, E. M. (2000): Ancient Sculpture in the Allard Pierson Museum Amsterdam, Amsterdam.

MORENO PÉREZ, A. S. (2016): Pollentia (Islas Baleares. Hispania Citerior), CSIR España, I, 6, Granada-Tarragona.

NEUDECKER, R. (1988): Die Skulpturenausstattung römischer Villen in Italien, Mainz am Rhein.

NOGALES, T.; CARVALHO, A.; ALMEIDA, M. J. (2004): El programa decorativo de la Quinta das Longas (Elvas, Portugal): un modelo excepcional de las uillae de Lusitania, Actas de la IV Reunión sobre Escultura Romana en Hispania (T. Nogales, L. J. Gonçalves, coords.), Madrid, 103-156

ORTALLI, J.; NERI, D. (cur.) (2007): Immagine divine. Devozioni e divinità nella vita quotidiana dei Romani, testimonianza archeologique dall'Emilia Romagna, Firenze.

PEÑA, A. (2007-08): La escultura de domus en Hispania, Anales de la Universidad de Murcia 23-24, 119-144.

PUERTA, C.; ELVIRA, M. Á.; ARTIGAS, T. (1994): La colección de esculturas hallada en Valdetorres de Jarama, AEspA 67, 179-200.

RODRÍGUEZ OLIVA, P.; BELTRÁN, J.; BAENA, L. (2016): La decoración escultórica, Las villas romanas de la Bética $(\mathrm{R}$. Hidalgo, coord.), Sevilla, 463-490.

STIRLING, L. M. (2005): The Learned Collector - Mythological Statuettes and Classical Taste in Late Antique Gaul, Ann Arbor.

STUVERAS, R. (1969): Le putto dans l'art romain, Bruxelles.

VIDAL, R. (2019): El jaciment romà de les Hortes de Xaló, Actes 6é Congrés d'Estudis de la Marina Alta, I, Pego, 119-134.

VIDAL, R.; ORTOLÀ, M. (2010): El forn terrisser romà de l'avinguda de les Hortes de Xaló, La memòria del nostre passat, Ajuntament de Xaló, 39-52.

VIDEBECH, CH. (2015): Private Collections of Sculpture in Late Antiquity: An Overview of the Form, Function and Tradition, Tradition. Transmission of Culture in the Ancient World (J. Fejfer, M. Moltessen, A. Rathje, eds.), Copenhagen, 451-479. 